\title{
Evaluation of Candidate Reference Genes for Quantitative Gene Expression Studies in Tree Peony
}

\author{
Lin Zhou', Qianqian Shi', Yan Wang', Kui Li, Baoqiang Zheng, and Kun Miao \\ State Key Laboratory of Tree Genetics and Breeding, Key Laboratory of Tree Breeding and \\ Cultivation of State Forestry Administration, Research Institute of Forestry, Chinese Academy of \\ Forestry, Beijing 100091, China
}

\begin{abstract}
AdDitional INDEX words. flower color, tissue, development stage, qRT-PCR, geNorm, NormFinder, BestKeeper
Abstract. Quantitative real-time reverse transcription polymerase chain reaction (RT-PCR) is a sensitive and widely used technique for gene expression analysis that depends on stability of the reference genes used for data normalization. Tree peony (Paeonia suffruticosa), known as one of the most famous traditional ornamental plants in China, is very popular in both domestic and international markets for its showy and colorful flowers. To date, no systematic studies on reference genes have been performed in tree peony with different flower colors. In this study, we evaluated the expression stability of 12 candidate reference genes in different tissues and five flower developmental stages of tree peony with six different colors by three algorithms: geNorm, NormFinder, and BestKeeper. The results showed that protein phosphatase $2 \mathrm{~A}(P P 2 A)$, ubiquitin protein ligase $(U P L)$, and ubiquitin $(U B Q)$ were the most stable genes across all samples. Helicase, alpha-tubulin (TUA), and eukaryotic translation initiation factor 5A (EIF5A) also exhibited high expression stability in different tissues, in samples with different colors, and at different flower developmental stages. According to the geNorm analysis, the combination of two most stable reference genes was optimal for normalization in all tested sample sets in this study. To further validate the suitability of the reference genes identified in this study, the expression patterns of two putative homologs of chalcone synthase gene (PsCHS1) and chalcone isomerase gene (PSCHI1) were studied at different developmental stages of white flowers. The results provide information for transcriptional analyses in future studies of gene expression on tree peony flower development and pigmentation.
\end{abstract}

Gene expression analysis is increasingly important to understand the molecular mechanisms of plant biological processes, such as growth and development, and biotic and abiotic stress responses (Huang et al., 2010; Koo et al., 2010; Ren et al., 2010). Compared with the traditional methods to measure transcript expression levels including northern blotting, ribonuclease (RNase) protection analysis, in situ hybridization, and semiquantitative RT-PCR, quantitative RT-PCR (qRT-PCR) has been widely considered as the most reliable method for gene expression analysis because of its sensitive, specific, and reproducible quantification of nucleic acids (Ginzinger, 2002; Heid et al., 1996; Nolan et al., 2006). However, the accuracy of qRT-PCR is influenced by a number of elements, such as ribonucleic acid (RNA) stability, quantity, purity, variations in complementary deoxyribonucleic acid (cDNA) synthesis efficiency, and differences in the overall transcriptional activity of the tissues or cells analyzed (Vandesompele et al., 2002). Therefore, to obtain reliable quantitative gene expression results, selection of a suitable normalization method is a crucial prerequisite (Freeman et al., 1999; Udvardi et al., 2008).

The most common normalization approach is to use appropriate reference genes that are presumed to have stable expression among different tissues and at all developmental stages, regardless of the experimental conditions or treatments

Received for publication 16 June 2015. Accepted for publication 17 Nov. 2015. This work was financially supported by National Natural Science Foundation of China (Grant No. 31201654) and the National High Technology Research and Development Program of China (863 Program) (Grant No. 2011AA10020701). ${ }^{1}$ These authors contributed equally to this work and should be considered as co-first authors.

${ }^{2}$ Corresponding author. E-mail: wyancaf@163.com.
(Bustin et al., 2009; Guenin et al., 2009). The traditional reference genes including actin $(A C T), U B Q, T U A$, beta-tubulin $(T U B), 18 \mathrm{~S}$ ribosomal RNA (18S $r R N A)$, glyceraldehyde-3phosphate dehydrogenase $(G A P D H)$, and elongation factor 1-alpha $(E F 1 \alpha)$ have been mostly used in model and nonmodel plants (Brunner et al., 2004; Czechowski et al., 2005; Jain et al., 2006). However, many studies have shown that they do not always maintain stable expression levels among different tissues, experimental conditions, or species/cultivars (Chandna et al., 2012; Jin et al., 2013; Lin et al., 2013; Lovdal and Lillo, 2009; Migocka and Papierniak, 2011; Wang et al., 2014a). Recently, some novel reference genes showing highly stable expression were identified by microarray analysis in arabidopsis [Arabidopsis thaliana (Czechowski et al., 2005)] and soybean [Glycine max (Libault et al., 2008)], such as PP2A,EIF5A, cyclophilin (CYP), and others. Many of these reference genes outperform the traditional ones. For example, $P P 2 A$ in hybrid rose [Rosa hybrida (Klie and Debener, 2011)], mei [Prunus mume (Wang et al., 2014b)], and chrysanthemum [Chrysanthemum $\times$ morifolium (Hong and Dai, 2015)]; EIF5A in poplar [Populus (Brunner et al., 2004)]; and $C Y P$ in soybean (Jian et al., 2008) and rhododendron (Rhododendron micranthum) (Yi et al., 2012). Thus, a systematic validation of potential reference genes is critically important for certain experimental conditions and among various species before their use in qRT-PCR normalization (Czechowski et al., 2005; Guenin et al., 2009).

To date, although studies of reference gene expression in plants have mainly focused on model and important crop species, such as arabidopsis (Czechowski et al., 2005), wheat [Triticum aestivum (Paolacci et al., 2009)], poplar (Brunner et al., 2004), tomato [Solanum lycopersicum (Expósito-Rodríguez et al., 2008)], cotton [Gossypium hirsutum (Artico et al., 2010)], 


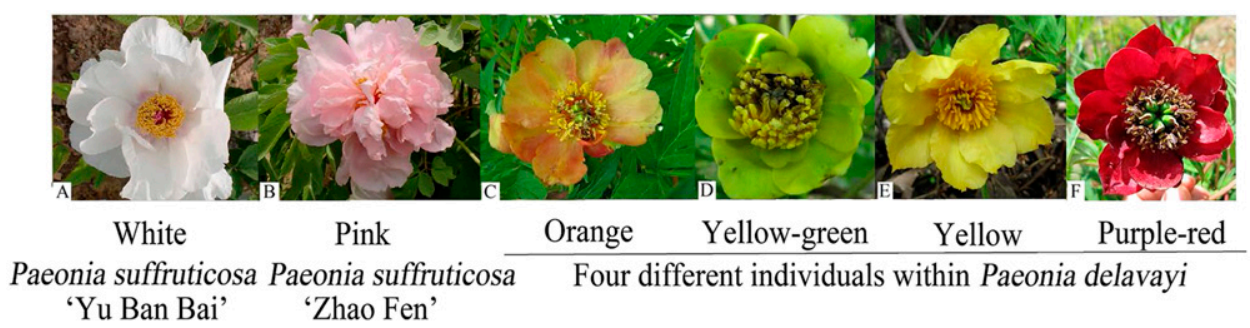

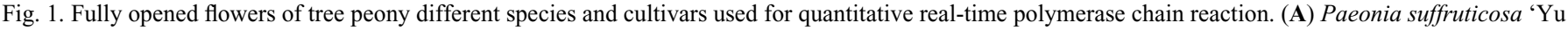
Ban Bai' (white-flowered cultivar). (B) P. suffruticosa 'Zhao Fen' (pink-flowered cultivar). (C-F) Separate individuals with orange, yellow-green, yellow, and purple-red flowers within a wild population of $P$. delavayi.

grapevine [Vitis vinifera (Coito et al., 2012)], and peanut [Arachis hypogaea (Reddy et al., 2013)], many stable reference genes have been screened in several ornamental plants including petunia [Petunia hybrida (Mallona et al., 2010)], hybrid rose (Klie and Debener, 2011), rhododendron (Yi et al., 2012), cineraria [Senecio cruentus (Jin et al., 2013)], and chrysanthemum (Fu et al., 2013).

Tree peony is a very famous traditional ornamental and medicinal plant in China and is also appreciated internationally because of its large, showy, and colorful flowers ( $\mathrm{Li}, 1999)$. There are nine wild species of tree peony, $P$. suffruticosa, Paeonia cathayana, Paeonia jishanensis, Paeonia qiui, Paeonia ostii, Paeonia rockii, Paeonia decomposita, Paeonia delavayi, and Paeonia ludlowii, and $\approx 1500$ cultivars in the world with a wide range of flower colors have been produced by conventional breeding (Hong and Pan, 2005a, 2005b, 2007). Among all the species, $P$. delavayi is unique with various colors in all floral parts (Hong et al., 1998). Various petal colors can be found in the same population of $P$. delavayi, including yellow, orange, red, dark red, yellow-green, or purple-red (Hong et al., 1998; Li et al., 2011), among which plants with yellow flowers are considered to be the most important resource for cultivar development because the flower color in existing Chinese cultivars are purple, pink, red, and white, but lack pure yellow. In our recent study, transcriptome profiles were compared between yellow and purple-red individuals of $P$. delavayi by Illumina HiSeq RNA sequencing, and a number of differently expressed genes involved in the flower pigmentation as well as many potential reference genes were identified (Shi et al., 2015). To elucidate the molecular mechanism of $P$. delavayi flower coloration, further research is required to analyze expression patterns of particular genes at each stage of flower development and among different colors and tissues based on the selection of ideal reference genes for qRT-PCR analysis. In a previous study, some reference genes were evaluated in various tissues (roots, stems, leaves, and petals) and petals of a tree peony cultivar during different opening phases or under different treatments with ethylene or glucose (Wang et al., 2012). However, all of these genes are traditional and commonly used housekeeping genes. Moreover, there is no other systematic analysis that has been performed for the selection of suitable reference genes in different tissues or at different flower developmental stages of tree peony across different wild species with different flower colors, thereby limiting further studies on this plant at the transcriptome level.

In this study, tree peony orthologs of 12 arabidopsis reference genes were identified based on our previous trancriptome analysis, including six traditional housekeeping genes, $A C T 2, G A P D H, T U A, E F 1 \alpha, T U B$, and $U B Q$ and six newly identified candidate reference genes, CYP, EIF5A, helicase, $P P 2 A, U B C$, and $U P L$. These candidate reference genes were evaluated for analysis of their expression stabilities in petals at five flower developmental stages and in different tissues at full opening stage of $P$. suffruticosa and $P$. delavayi with six different flower colors. Three statistical algorithms, geNorm (Vandesompele et al., 2002), NormFinder (Andersen et al., 2004), and BestKeeper (Pfaffl et al., 2004), were used to determine the most suitable reference gene(s). Finally, to verify the usefulness of the stable gene(s) calculated by the software, the expression patterns of two flavonoid-biosynthetic genes, PsCHS1 (GenBank accession no.GQ483511) and PsCHII (GenBank accession no.GQ984161) (Zhou et al., 2011, 2014) were analyzed in petals during flower pigmentation. Our results will benefit further studies on the gene expression of tree peony and other species of the Paeoniaceae family.

\section{Materials and Methods}

Plant materials. Four separate individuals with purple-red, yellow, yellow-green, or orange flowers within a wild population of $P$. delavayi in Shangri-La County (lat. $27^{\circ} 57^{\prime} \mathrm{N}$, long. $99^{\circ} 35^{\prime} \mathrm{E}$ ), Yunnan Province, China, and two P. suffruticosa cultivars, P. suffruticosa 'Zhao Fen' (pink-flowered cultivar) and 'Yu Ban Bai' (white-flowered cultivar), grown in the peony nursery of Chinese Academy of Forestry, Beijing, China, were used in this study (Fig. 1). Petal samples were separately detached at five flower developmental stages from the end of April to early May 2014. An index for the developmental stages of flower bud opening in tree peony was described as follows: stage 1 , unpigmented tight bud; stage 2 , slightly pigmented soft bud; stage 3, initially opened flower; stage 4, half opened flower; stage 5, fully opened and pigmented flower with exposed anthers (Zhou et al., 2011). Leaves, stems, sepals, stamens, and carpels were excised from flower branches at full opening stage (stage 5). Samples were collected from three plants to provide three biological replicates. Plant tissues were immediately frozen in liquid nitrogen and after transport to the laboratory stored at $-80^{\circ} \mathrm{C}$ until RNA extraction.

RNA EXTRACTION AND CDNA sYNTHESIS. Total RNA was extracted from all samples by the cetyltrimethylammonium bromide method with some modifications (Chang et al., 1993), and then genomic DNA was eliminated using RNase-free DNase I (Tiangen, Beijing, China). RNA purity and concentration were assessed using a spectrophotometer (NanoDrop 2000; Thermo Fisher Scientific, Waltham, MA), and integrity was verified using $1.2 \%$ agarose gel electrophoresis with Goldview staining (SBS Genetech, Beijing, China). Samples with concentrations greater than $100 \mathrm{ng} \cdot \mu \mathrm{L}^{-1}$, an optical density 
absorption ratio A260/A280 greater than 1.8 and without smears on the agarose gel, were used for the following experiment. First-strand cDNA was synthesized from $240 \mathrm{ng}$ of total RNA in a final volume of $20 \mu \mathrm{L}$ with oligo $(\mathrm{dT})_{18}$ primer using the PrimeScript ${ }^{\circledR}$ RT reagent kit (TaKaRa Biotechnology, Dalian, China) according to the manufacturer's protocol. The cDNA sets were stored at $-20{ }^{\circ} \mathrm{C}$ and diluted 1:6 with nuclease-free water before qRT-PCR analyses.

Selection of CANDidate REFERENCE Genes. Based on the homology analysis of tree peony transcriptome data, sequences of 12 potential reference genes were obtained. A BLASTX ( $E$-value $\leq 10^{-6}$ ) was then conducted against the relevant sequences of arabidopsis genes from genome-wide investigation of arabidopsis (Czechowski et al., 2005) to confirm the gene homologs in tree peony. The 12 candidate reference genes comprised six traditional housekeeping genes including $A C T 2$, $G A P D H, T U A, E F 1 \alpha, T U B$, and $U B Q$ and six newly identified ones including $C Y P, U B C, E I F 5 A$, helicase, $U P L$, and $P P 2 A$, which were assessed in later expression analyses (Table 1).

Primers were designed using the Primer Premier 5.0 software (Premier Biosoft International, Palo Alto, CA) with the following parameters: melting temperatures 60 to $65^{\circ} \mathrm{C}$, primer lengths $17-25 \mathrm{bp}, \mathrm{GC}$ (guanine-cytosine) content $45 \%$ to $55 \%$, and amplicon lengths $80-150 \mathrm{bp}$. To confirm the products size and specificity, amplicons of each primer pair were analyzed by $2.5 \%$ agarose gel electrophoresis and sequenced by Sangon Biotech (Shanghai, China). For each primer pair, a series of five 10-fold dilutions of the pooled cDNA were made to determine the gene specific PCR amplification efficiency. Based on the threshold cycle $(\mathrm{Ct})$ values for all dilution points in a series, a standard curve was generated using linear regression. Efficiency of PCR with each primer pair was calculated using the slope of the regression line with following equation: Efficiency $=$ $10^{(-1 / \text { slope })} \times 100 \%$. The primers that displayed efficiency values between $90 \%$ and $105 \%$ were selected for qRT-PCR. Detailed information on the selected primers is shown in Table 1.

REAL-TIME QRT-PCR ASSAYS. qRT-PCR reactions were performed on an ABI Prism 7500 Sequence Detector (Applied Biosystems, Foster City, CA) using SYBR Premix Ex Taq ${ }^{\mathrm{TM}} \mathrm{Kit}$ (TaKaRa Biotechnology) in a $20-\mu \mathrm{L}$ reaction volume containing $2 \mu \mathrm{L}$ of the diluted cDNA, $200 \mathrm{nM}$ of each gene specific primer, $10 \mu \mathrm{L}$ of $2 \times$ SYBR Premix Ex Taq ${ }^{\mathrm{TM}}, 0.4 \mu \mathrm{L}$ of ROX Reference Dye (TaKaRa Biotechnology), and $6.8 \mu \mathrm{L}$ of doubledistilled $\mathrm{H}_{2} \mathrm{O}$. The reaction conditions were the following: $95^{\circ} \mathrm{C}$ for $30 \mathrm{~s}, 40$ cycles of $95^{\circ} \mathrm{C}$ for $5 \mathrm{~s}$, and $60{ }^{\circ} \mathrm{C}$ for $34 \mathrm{~s}$. A no template control was also included in each run for each gene. To control the consistency and specificity of PCR amplification, dissociation curves were recorded after 40 cycles by heating the amplicon from 60 to $95{ }^{\circ} \mathrm{C}$. All qRT-PCR reactions were carried out in biological and technical triplicate. The $\mathrm{Ct}$ values were automatically determined using SDS version 2.3 (Applied Biosystems) software with default parameters.

Statistical analysis. To rank the expression stability of reference genes across all of the experimental sets, three different types of Excel (Microsoft, Redmond, WA)-based software: geNorm, NormFinder, and BestKeeper were used. For geNorm and NormFinder, the raw $\mathrm{Ct}$ values were transformed into relative quantities using the formula: $2^{-\Delta \mathrm{Ct}}$, in which $\Delta \mathrm{Ct}=$ each corresponding $\mathrm{Ct}$ value - minimum $\mathrm{Ct}$ value. The maximum expression level (the lowest $\mathrm{Ct}$ value) of each gene was used as a calibrator and was set to a value of 1 . BestKeeper analyses were based on untransformed $\mathrm{Ct}$ values. All three software packages were used according to the manufacturer's instructions. All other multiple comparisons were performed with SPSS 17.0 (IBM Corp., Armonk, NY).

Normalization of PsCHS1 and PsCHI1. To demonstrate the usefulness of the validated candidate reference genes in qRT-PCR, the expression patterns of two independent target genes PsCHS1 and PSCHI1, which were cloned by our laboratory (Zhou et al., 2011, 2014) were studied. The expression levels of $P s C H S 1$ and $P s C H I 1$ in petals at five flower developmental stages of $P$. suffruticosa 'Yu Ban Bai' were quantified using individual stable or unstable genes or a combination of stable reference genes determined by the software. Primer pairs of $P S C H S 1$ and $P S C H I 1$ are presented in Table 1. For data analysis, the relative expression ratios were calculated by the comparative $\Delta \Delta \mathrm{Ct}$ method (ABI Prism 7500 Sequence Detection System, Applied Biosystems) of relative gene quantification. The expression levels of these two genes during flower development were achieved by calibrating the transcription level in petals at different stages to that at stage 1. The expression level calculated by the Eq. $2^{-\Delta \Delta \mathrm{Ct}}$ represents the $\mathrm{x}$-fold difference from the calibrator.

\section{Results}

Primer SPECIFICITY AND AMPLIFICATION EFFICIENCY ANALYSIS. To determine the specificity of each primer pair designed in the current study, agarose gel electrophoresis with Goldview staining (SBS Genetech) and melting curve analyses were performed. As shown in Supplemental Fig. 1, all primer pairs amplified a single band of the expected size, and the PCR products were further confirmed by sequencing (Supplemental Table 2). Melting curve analyses following the qRT-PCR experiment also validated the specificity of all amplicons as only a single peak was present (Supplemental Fig. 2). No qRT-PCR signals were detected in the no-template controls and reverse-transcription negative control samples. Further, standard curves for amplification reactions were generated using 10-fold serial dilutions of cDNA to calculate the gene-specific PCR efficiency and the correlation coefficients $\left(R^{2}\right)$ (Supplemental Fig. 3). The qRT-PCR amplification efficiency of the 12 reference genes varied from $90.53 \%$ for $U B C$ to $104.98 \%$ for $U P L$ (Table 1 ), and $R^{2}$ for all standard curves were $>0.99$ (Supplemental Fig. 3). Generally, PCR efficiency between $90 \%$ and $105 \%$ is considered to be acceptable (Fu et al., 2013; Kong et al., 2014). Thus, all primers designed were available for further qRT-PCR assays.

EXPRESSION PROFILING OF CANDIDATE REFERENCE GENES. TO examine the expression stability of the 12 candidate genes, a qRT-PCR assay based on SYBR Green dye detection was carried out. As shown in Fig. 2, the 12 reference genes showed relatively wide ranges of $\mathrm{Ct}$ values across all samples. The mean $\mathrm{Ct}$ values of the reference genes ranged from 19 to 27 , with most of the $\mathrm{Ct}$ values between 22 and 24 cycles. $U B Q$ was the most abundant reference gene of the set, which exhibited a mean Ct value of 19.65. ACT2 showed the lowest level of expression in all samples with a mean Ct value as high as 26.97. The calculated $\mathrm{CV}$ of the $\mathrm{Ct}$ values provides an indication of the expression stability of a particular gene. The narrower range of the $\mathrm{Ct}$ values, the more stable of the given gene expression. Among the 12 candidate reference genes in this study, EIF5A had the lowest range of $\mathrm{Ct}$ values, with a $\mathrm{CV}$ value of $4.66 \%$, whereas CYP had a much higher $\mathrm{Ct}$ range than the other genes, with a $\mathrm{CV}$ value of $25.96 \%$, indicating the most variable expression profile 


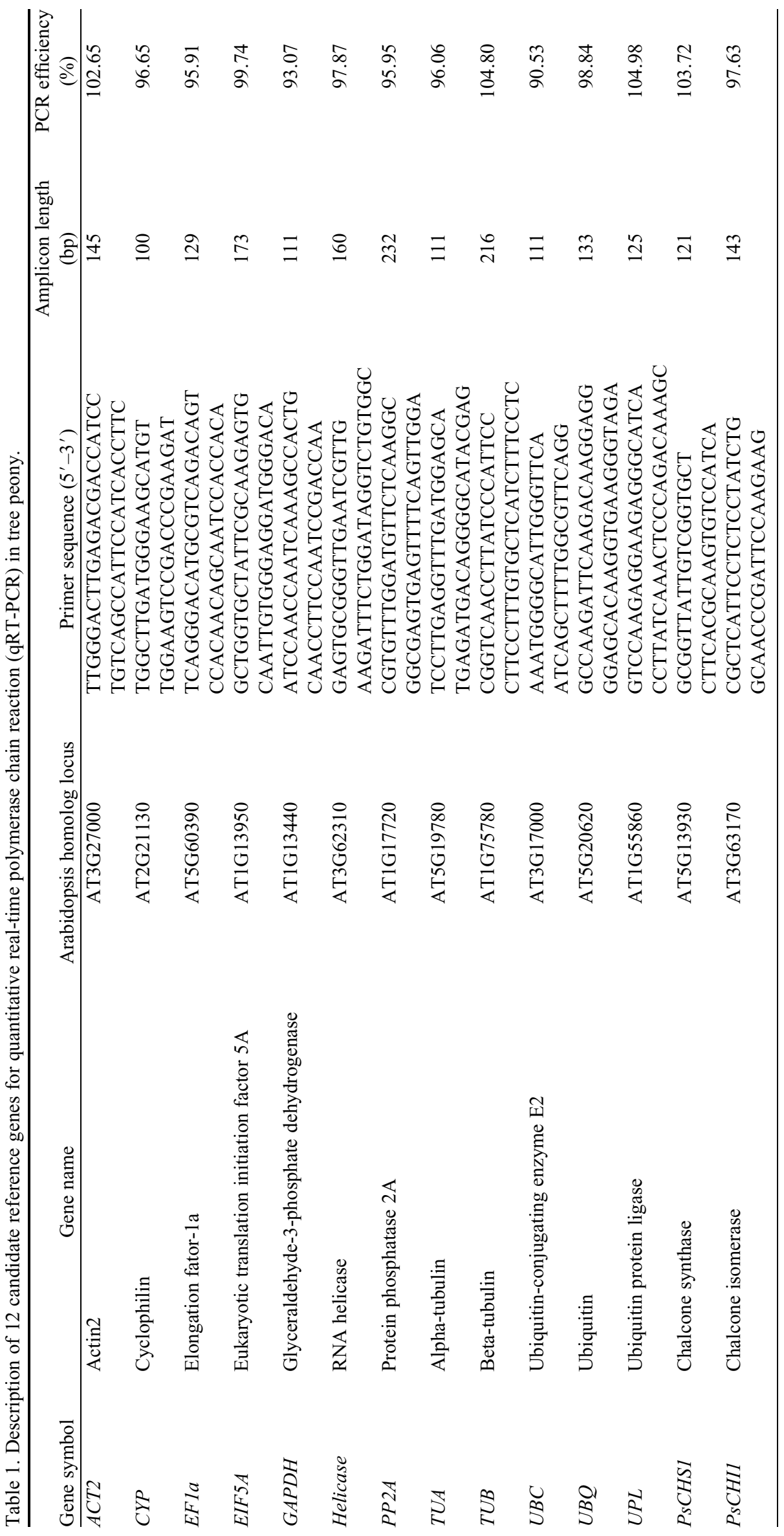




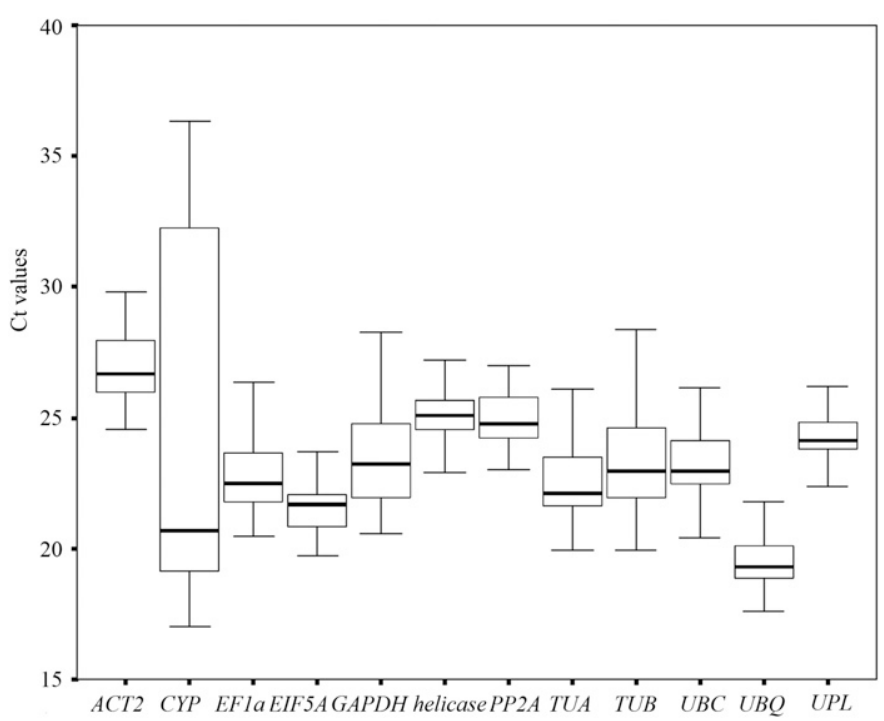

Fig. 2. Mean threshold cycle $(\mathrm{Ct})$ values of 12 candidate reference genes across all sample sets of tree peony. Lines across the boxes are the medians. Boxes indicate the 25/75percentiles. Whisker caps represent the maximum and minimum values.

across all samples. These results suggested that simple comparison of the raw $\mathrm{Ct}$ values of the candidate reference genes could not provide sufficient information for the expression stability evaluation, and none of the selected genes were expressed stably in all samples. Therefore, the following analysis using three different statistical algorithms was used to identify the most reliable reference gene for gene expression studies in tree peony.

GENorm ANALYsis. The expression stability of the 12 candidate genes was measured and ranked using the geNorm software. geNorm uses an algorithm to calculate the average expression stability $(M)$ and is based on the principle that the expression ratio of two ideal reference genes should be constant throughout the different groups of templates. The gene with the lowest $M$ value is that with the most stable expression, whereas the gene with the highest $M$ value has the least stable expression. As shown in Fig. 3, PP2A, UPL, and helicase were identified as the most stable genes across all samples, whereas $C Y P$ and $T U B$ were the least stable transcripts, in order. Among the petals with different colors, helicase, $U P L$, and $P P 2 A$ were the most stable genes, whereas in different tissues, $P P 2 A, U P L$, and helicase were the most stable genes. At different developmental stages during flower opening, helicase, $P P 2 A$, and $A C T 2$ were the most stable genes and $C Y P$ was the most variable. In addition, the results of the geNorm analysis on the single-colored samples at different developmental stages indicated that $A C T 2, P P 2 A$, and $U P L$ were the most stably expressed genes in white and yellow-green-colored samples; $A C T 2, T U A$, and $P P 2 A$ were expressed more stably in pinkcolored samples, followed by helicase and UPL; helicase, TUA, and $P P 2 A$ were the most stably expressed genes in yellowcolored samples; $U B Q, U B C$, and helicase were the most stable genes in orange-colored samples, followed by $A C T 2$ and $P P 2 A$. In purple-red-colored samples, $M$ values of all genes were similar and less than 0.07 , indicating that the 12 genes had stable expression, of which $U B C, U B Q$, and helicase were the most stable genes. Overall, evaluation of all expression data revealed that $P P 2 A, U P L$, and helicase were the most stably expressed genes; therefore, these may be suitable reference gene for gene expression analyses in a wide variety of tissue types and developmental stages in tree peony different species and cultivars with different flower colors.

The optimal number of reference genes was also calculated by the geNorm program for accurate normalization among the different sample sets. The pairwise variation $\left(\mathrm{V}_{\mathrm{n}} / \mathrm{V}_{\mathrm{n}}+{ }_{1}\right)$ between sequential normalization factors (NFs) $\left(\mathrm{NF}_{\mathrm{n}}\right.$ and $\mathrm{NF}_{\mathrm{n}+1}$ ) was determined as an indicator. A large variation means that the added gene is necessary for calculation of a reliable NF, with a cut-off value of 0.15 being generally recommended (Vandesompele et al., 2002). As shown in Fig. 4, the inclusion of the fourth gene had no significant effect $(\mathrm{V} 2 / 3=0.1516, \mathrm{~V} 3 / 4=0.1488)$ for all samples, so three reference genes would be optimal for normalizing gene expression under those conditions. Similarly, three reference genes would be requisite for tree peony different tissues (V2/3= $0.1674, \mathrm{~V} 3 / 4=0.1254)$. In the expression analyses on various colored flower petals at different developmental stages, two genes would be sufficient (all the V2/3 values were lower than 0.15 ) for a reliable normalization.

NormFinder ANALYSIS. The stability of potential reference genes was reanalyzed using NormFinder to confirm the results obtained by geNorm. NormFinder is based on intra- and intergroup variations and combines both results into a stability value for each candidate reference gene (Andersen et al., 2004). Genes were then ranked according to their stability under a given set of experimental conditions. In each colored petals at different developmental stages, the NormFinder analysis ranked $A C T 2, P P 2 A$, and helicase as the most stable genes in white-colored samples; $A C T 2, E F 1 a$, and $U P L$ in orangecolored samples; $P P 2 A, A C T 2$, and $U P L$ in pink-colored samples; $A C T 2, P P 2 A$, and $G A P D H$ in yellow-green-colored samples; $T U A$, helicase, and $A C T 2$ in yellow-colored samples; and $A C T 2, U B C$, and $U B Q$ in purple-red-colored samples, which was similar with the results obtained from geNorm (Fig. 3; Table 2). However, when evaluated across all experimental samples, although NormFinder and geNorm both indicated $T U B$ and $C Y P$ as the least stable genes, some slight differences were observed between the calculation results of these two algorithms (Fig. 3; Table 2); NormFinder analysis ranked $E F 1 a, U B Q$, and $P P 2 A$ as most stable genes, whereas $U B Q$ and $E F 1 a$ were ranked third and eighth, respectively, by geNorm. Meanwhile, among the different tissues, $P P 2 A, U B Q$, and EFIa were in the top positions, whereas geNorm ranked $E F 1 a$ in the ninth position. In samples of different developmental stages, UPL and GAPDH were calculated to be the most stably expressed genes, while they were ranked fifth and eighth by geNorm, respectively. In addition, among the samples with different colors, TUA and EFla were predicted as the best internal controls, while they were ranked fifth and seventh by geNorm, respectively.

BestKeEper Analysis. BestKeeper was used to analyze the stabilities of candidate reference genes based on the coefficient of correlation to the BestKeeper index, which is the geometric mean of the $\mathrm{Ct}$ values of all candidate reference genes (Pfaffl et al., 2004). BestKeeper also calculates the and cv based on the $\mathrm{Ct}$ values of all candidate reference genes (Pfaffl et al., 2004). Reference genes are identified as the most stable genes when they exhibit the lowest $\mathrm{CV} \pm$. In this study, the results showed that EIF5A,UPL, UBQ, PP2A, and helicase had $\mathrm{CV} \pm$ values of $3.43 \pm 0.74,3.45 \pm 0.85,4.63 \pm 0.91,3.64 \pm 0.91$, and $3.63 \pm$ 0.92 , respectively, and showed stable expression in all samples 

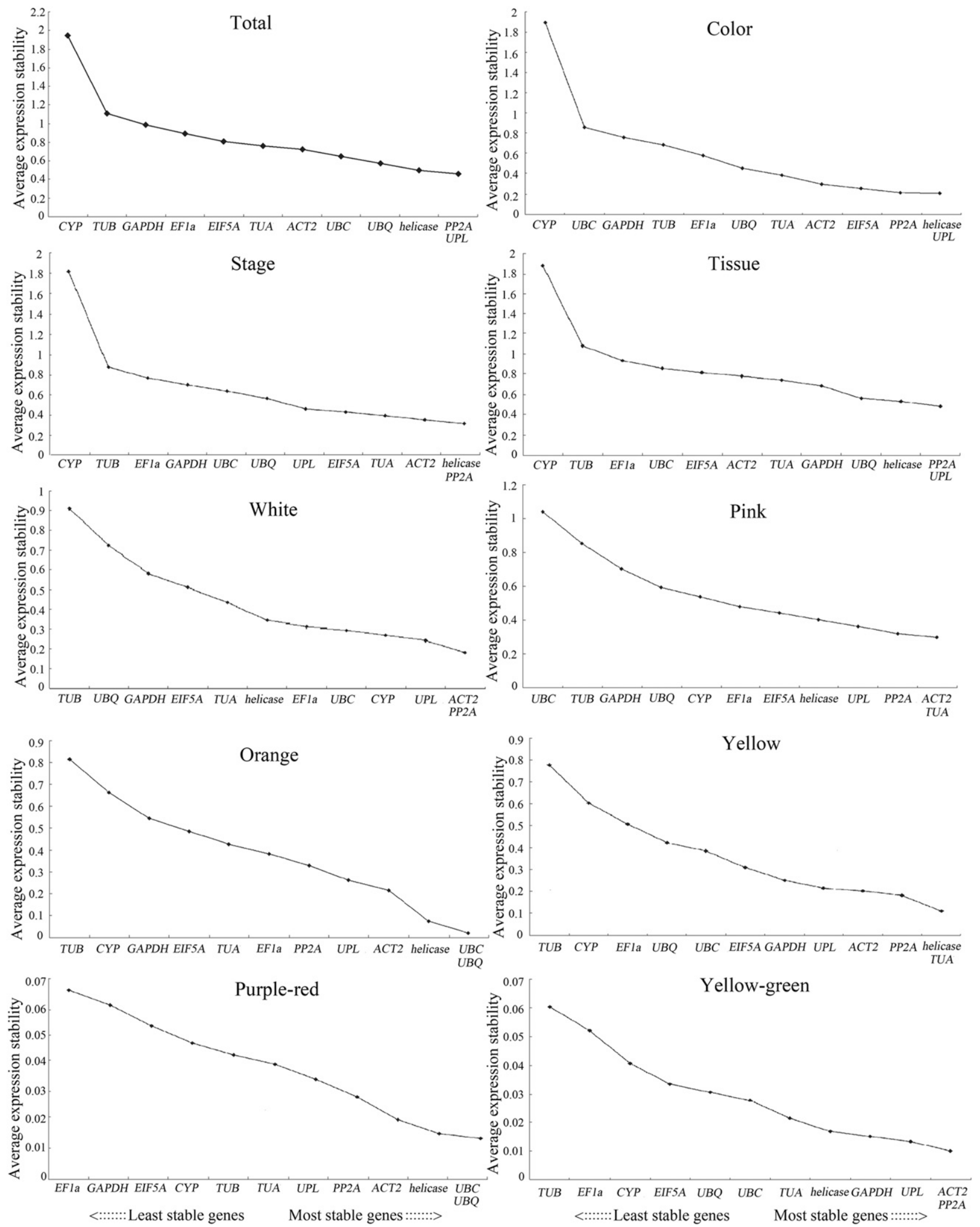

Fig. 3. Expression stability and ranking of 12 candidate reference genes of tree peony as calculated by geNorm software (Vandesompele et al., 2002). The average expression stability $(M)$ was calculated following stepwise exclusion of the least stable gene across all the samples within an experimental set. The lowest $M$ value indicates the most stable gene, whereas the highest value represents the most variable gene. 


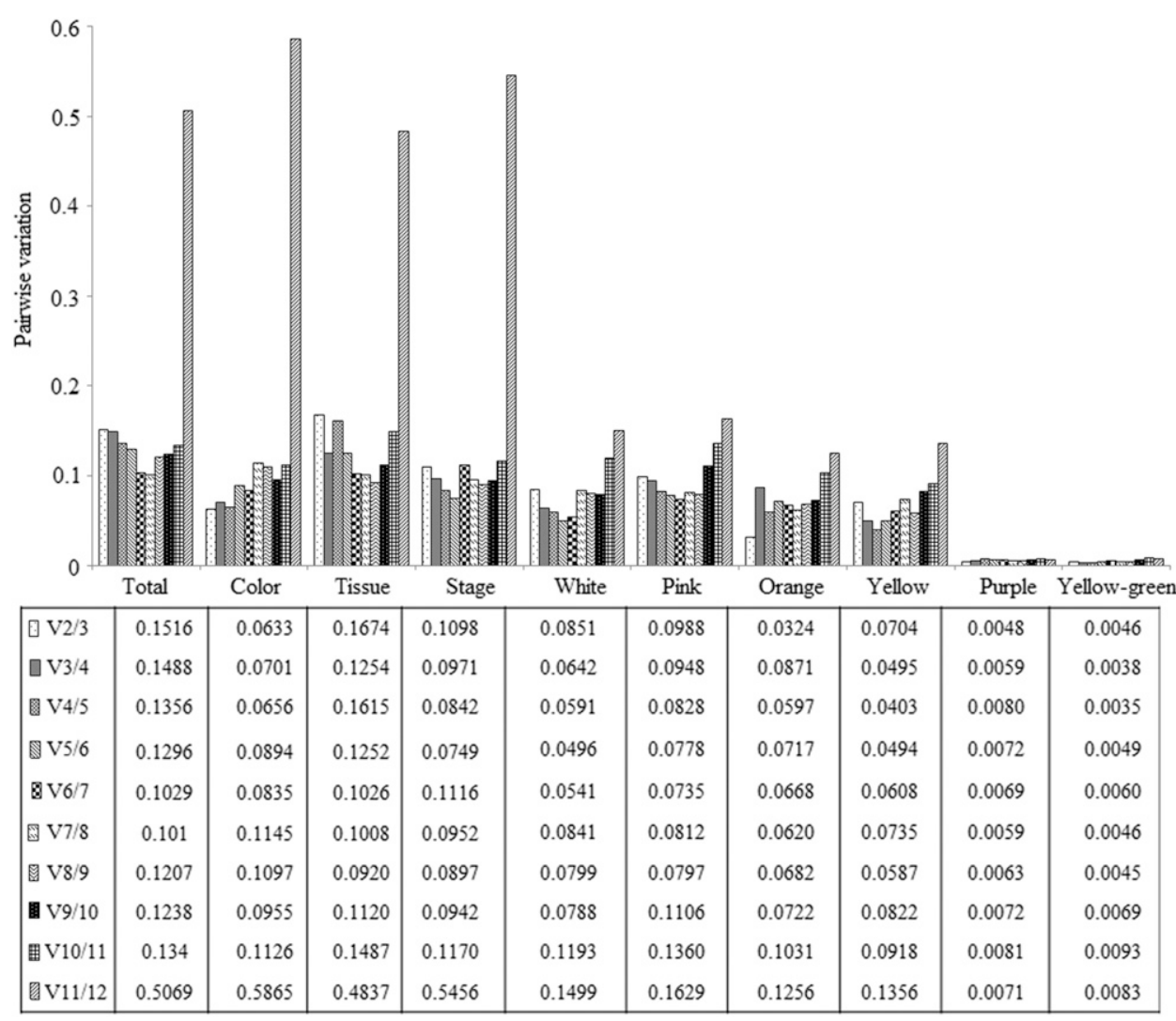

Fig. 4. The optimal number of reference genes required for effective normalization in each experimental set of tree peony. The pairwise variation $\left(\mathrm{V}_{\mathrm{n}} / \mathrm{V}_{\mathrm{n}+1}\right)$ was analyzed between normalization factors $\mathrm{NF}_{\mathrm{n}}$ and $\mathrm{NF}_{\mathrm{n}+1}$ by geNorm program to determine the optimal number of reference genes (Vandesompele et al., 2002).

(stages 1 to 3 ), and thereafter declined rapidly when flowers half opened (stage 4) to the lowest expression level at full-opening (stage 5). However, when normalized with the least stable reference gene $T U B$, the expression pattern showed significant differences; PsCHS1 showed the lowest expression level at stage 2 and peaked at stage 5 with a significantly higher level, whereas PsCHII was at relatively high abundance from stages 1 to 3 , reduced rapidly at stage 4 , and then increased sharply and peaked at stage 5 .

\section{Discussion}

qRT-PCR has become the most suitable method for gene expression analysis because of its high throughput, sensitivity, accuracy, and large dynamic range (Artico et al., 2010; Silver et al., 2006; VanGuilder et al., 2008). In this technique, normalization with ideal reference genes is very important for accurate interpretation of variability. Tree peony is one of the most important traditional ornamental and medicinal plants in China with nine wild species, out of which $P$. delavayi is important in cultivar development

(Table 3), whereas EIF5A was ranked seventh by geNorm and 10th by NormFinder (Fig. 3; Table 2). Among the different tissues, EIF5A emerged as the most stable reference gene (ranked seventh by geNorm and 10th by NormFinder). In the sample sets under different flower developmental stages, UPL was the most stably expressed, and $P P 2 A$ and helicase were both calculated as the reliable genes with values less than 1 . For the sample sets with different colors, the most stable reference genes were EIF5A and TUA, followed by helicase, PP2A, and $U P L$. In addition, all reference genes exhibited similar and low $\mathrm{CV} \pm$ in each colored samples of different developmental stages, although their rank orders were slightly altered among different programs.

Reference Gene Validation. To validate the reliability of the selected reference genes, the relative expression patterns for two functional genes, $P s C H S$ land $P s C H I 1$, which play crucial roles in tree peony flavonoid biosynthesis, were analyzed at five flower developmental stages of $P$. suffruticosa ' $Y u$ Ban Bai' (a white-flowered cultivar) with the most stable genes ( $P P 2 A$ and $A C T 2$ singly or in combination). As a comparison, the mostunstable gene $(T U B)$ was also used for normalization in the analysis. As shown in Fig. 5, very similar expression patterns were obtained for each gene, with only slight differences when normalized using PP2A and ACT2 independently or the combination of them as reference genes. The transcript level of $P s C H S 1$ remained relatively unchanged before flowers half opened (stages 1 to 3), increased obviously from stage 4 , and peaked at stage 5 , when flowers were fully opened and pigmented; $P S C H I 1$ showed relatively high abundance in the early stages of flower opening due to its extremely variability of morphological characteristics, especially various petal colors including yellow, red, dark red, purple-red, orange, and yellow-green (Hong et al., 1998; Li et al., 2011). Studies on gene expression involved in the anthocyanin biosynthesis pathway would be beneficial for understanding the molecular mechanism of pigmentation in tree peony. For tree peony cut flowers, $U B Q$ and $G A P D H$ were considered as the most appropriate reference genes at different opening stages and under ethylene or glucose treatments (Wang et al., 2012), but up to now, no comprehensive or systematic evaluation of reference genes has been conducted among different tissues and different flower developmental stages of tree peony with different colors.

In this study, we selected 12 candidate reference genes (including six commonly used housekeeping genes of plants and six new candidate reference genes) whose sequence information was obtained from transcriptome data of $P$. delavayi and evaluated their expression stability among different tissues (petals, leaves, stems, sepals, stamens, and carpels) and in petal samples at five flower developmental stages of tree peony with different flower colors. Although the newly identified candidate reference genes were found to be among the most stably expressed in arabidopsis (Czechowski et al., 2005), they were tested only in few species due to the limited availability of their sequences. With the advent of next-generation sequencing, large-scale transcriptomic data became available for many plant species and these data presumably have a great potential as a source of candidate reference genes. Previous research (Demidenko et al., 2011; Wang et al., 2014b) and our results 


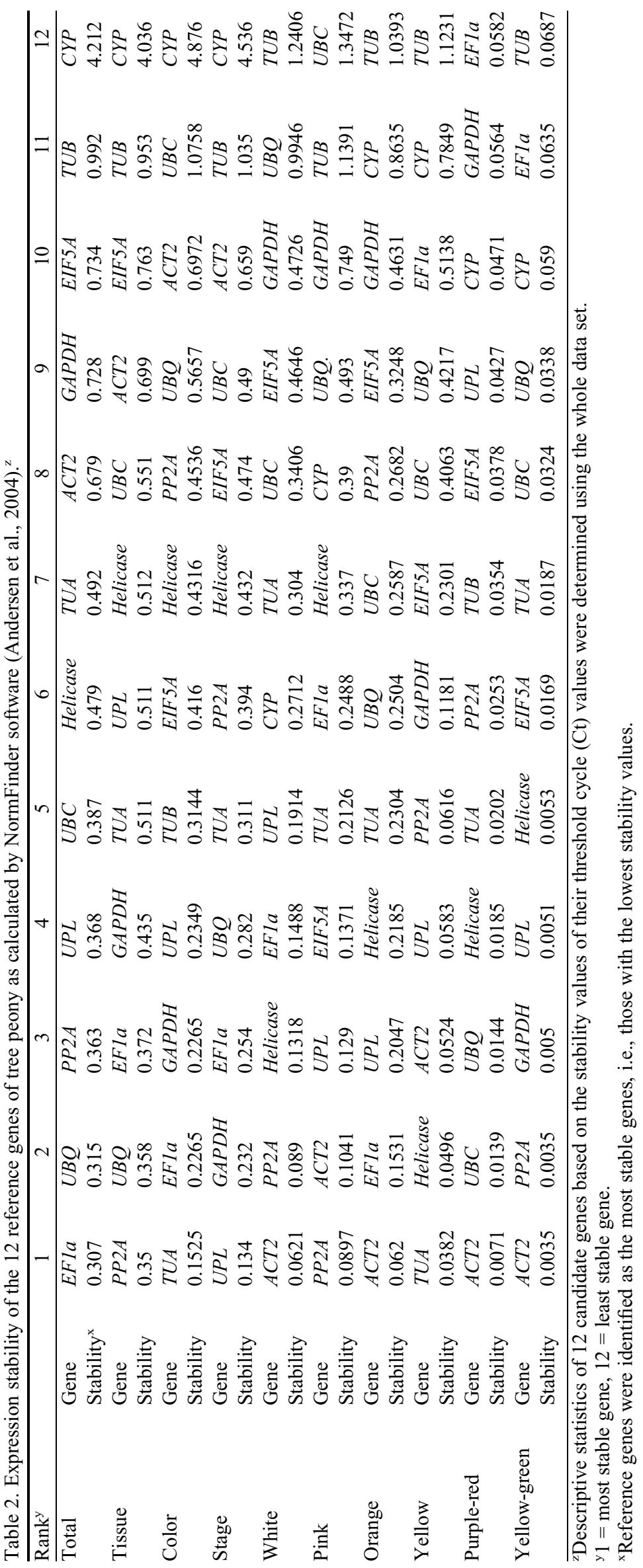




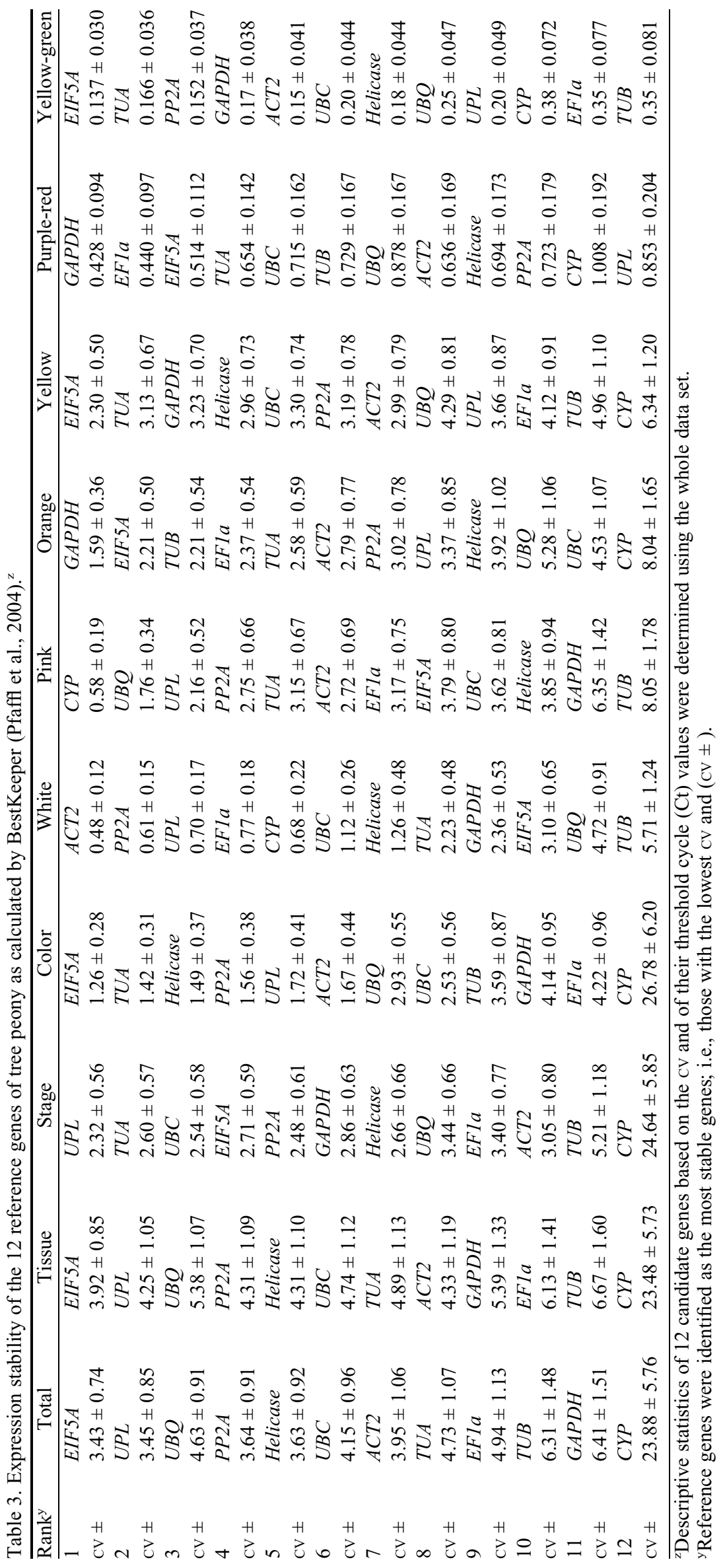



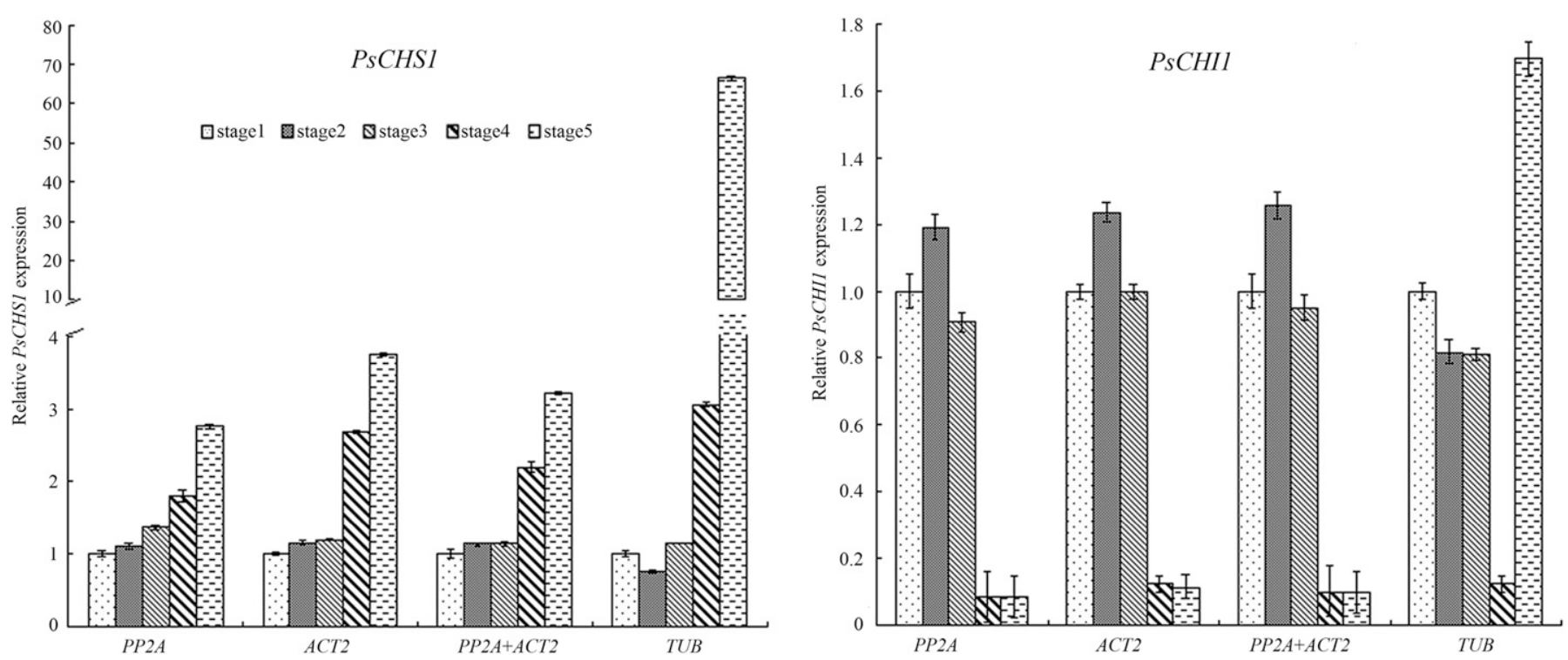

Fig. 5. The expression profiles of PsCHS1 and $P s C H I 1$ at different flower developmental stages of Paeonia suffruticosa 'Yu Ban Bai'. Normalization was performed using individual and combined reference genes: $P P 2 A, A C T 2, T U B$, and $P P 2 A+A C T 2$. The expression at stage 1 was used as a calibration standard. Error bars indicate sDs. $P S C H S 1=$ a chalcone synthase homolog gene of arabidopsis, $P S C H I 1=$ a chalcone isomerase homolog gene of arabidopsis, $P P 2 A=$ protein phosphatase $2 \mathrm{~A}$ gene, $A C T 2=$ actin2 gene, $T U B=$ beta-tubulin gene.

demonstrate that transcriptome sequencing data are indeed a useful source of potential reference genes. To select suitable reference genes for normalization, three algorithms were used including geNorm, NormFinder, and BestKeeper. These three programs are based on different principles, and a number of previous studies have demonstrated that contradictory results can be obtained when examining hybrid rose (Klie and Debener, 2011), cineraria (Jin et al., 2013), platycladus [Platycladus orientalis (Chang et al., 2012)], and peanut (Reddy et al., 2013). In the present research, the results from the three algorithms were largely similar. However, they did not identify exactly the same rank of the recommended reference genes for the different sample sets. Therefore, we considered the results of the three algorithms together when determining suitable reference genes for qRT-PCR normalization.

As shown in Supplemental Table 1, the top four stable reference genes were $P P 2 A$, UPL, helicase, and $U B Q$ using geNorm, whereas $E F 1 \alpha, U B Q, P P 2 A$, and $U P L$ were considered as the most stable genes by NormFinder, and using BestKeeper EIF5A, UPL, UBQ, and PP2A were in the top four positions when evaluated across all samples. Based on all three algorithms, $P P 2 A, U P L$, and $U B Q$ were suggested as the most stable genes across all samples. Among samples with different colors, helicase, UPL, PP2A, and EIF5A were identified using geNorm as the top four reference genes, while helicase was ranked seventh and third, $U P L$ was ranked fourth and fifth, $P P 2 A$ was ranked eighth and fourth, and EIF5A was ranked sixth and first using NormFinder and BestKeeper, respectively. According to these results, helicase, UPL, and EIF5A were suggested as the most stable genes in samples with different colors. The same strategy was used to determine suitable reference genes among different tissues and in samples at different stages. As a result, $P P 2 A, U P L$, and $U B Q$ were most suitable for normalization among different tissues, while $P P 2 A$, $U P L$, and TUA were most stable genes for normalization among samples of different developmental stages. As for each colored petals, geNorm calculated the $M$ values of all reference genes that were far less than the recommended cutoff value of 1.5 , suggesting that all of the genes exhibited stable expression (Fig. 3). Considering the fact that two genes would be sufficient (all the V2/3 values were lower than 0.15 ) for a reliable normalization, $P P 2 A$ and ACT2 were identified as the most stable genes in the white, pink, and yellow-green samples, helicase and TUA emerged as the most stably expressed in yellow samples, while $U B C$ and $U B Q$ were most appropriate for normalization in orange and purple-red samples. On the other hand, all three programs assessed $C Y P$ and $T U B$ as the least stable candidate reference genes for almost all sample sets, so they were not recommended for use in evaluation of tree peony flower development. These results were similar to those of previous studies. For example, $P P 2 A$ was considered as the most stable reference gene in different tissues and different developmental stages of hybrid rose (Klie and Debener, 2011), buckwheat [Fagopyrum esculentum (Demidenko et al., 2011)], cineraria (Jin et al., 2013), mei (Wang et al., 2014b), and chrysanthemum (Hong and Dai, 2015); UPL expressed stably in arabidopsis (Czechowski et al., 2005) and citrus [Citrus sp. (Mafra et al., 2012)]; ACT2 was the most suitable candidate reference gene for normalization in the analysis among different developmental stages of cineraria (Jin et al., 2013) and grapevine (Reid et al., 2006), and TUB was suggested to be an inappropriate internal control for qPCR analysis at different developmental stages and different tissues of tree peony cut flower (Wang et al., 2012), platycladus (Chang et al., 2012), grapevine (Reid et al., 2006), citrus (Mafra et al., 2012), and cineraria (Jin et al., 2013).

Among the 12 reference candidate genes used in the current study, UBQ, TUA, GAPDH, and EFl $\alpha$ have been considered as most commonly used reference genes. In many previous studies, $U B Q$ was determined to show a very stable expression level in arabidopsis (Czechowski et al., 2005) and tomato (Lovdal and Lillo, 2009), but was suggested to be unsatisfactory as a reference gene in soybean (Jian et al., 2008) and grapevine (Reid et al., 2006). In this article, $U B Q$ was ranked differently across various sample sets; it was ranked in the top four among all samples and different tissues by all three software 
programs but was calculated as the least stable gene in white flower samples of different developmental stages (Supplemental Table 1). TUA has also been widely used as a reference gene across various different stages of platycladus (Chang et al., 2012), different developmental stages of soybean (Jian et al., 2008), and different tissues of poplar (Brunner et al., 2004). In our study, TUA showed moderate stable expression among all different samples. $G A P D H$ was used as an appropriate internal control for qRT-PCR studies in hybrid rose (Klie and Debener, 2011), grapevine (Reid et al., 2006), and tree peony cut flower (Wang et al., 2012), but in chicory [Cichorium intybus (Maroufi et al., 2010)] and petunia (Mallona et al., 2010) it was proved to be much less stable. Here, we found that $G A P D H$ had moderate stability of expression in different tissues by all three software programs and showed stable expression in different petal colors and different developmental stages by NormFinder, but not geNorm and BestKeeper (Supplemental Table 1). The gene EF1 $\alpha$ encoding elongation factor 1-alpha has been commonly used as a reliable internal control due to its stable expression pattern under different conditions. For example, EF1 $\alpha$ emerged as the most appropriate reference genes for qPCR analysis in Litsea cubeba (Lin et al., 2013), poplar (Xu et al., 2011), across chicory leaf and root tissues (Maroufi et al., 2010), and during rhododendron leaf development (Yi et al., 2012). In the current study, EFl $\alpha$ was ranked in the bottom positions by geNorm and BestKeeper among different tissues, samples with different petal colors and samples at different developmental stages (Fig. 3; Table 3). The varied expression profiles of commonly used reference genes may be because they are involved in many other cellular processes besides their basic metabolic functions. Moreover, these results indicate that there are no universal reference genes for all plants species or different tissues and developmental stages of one species.

In addition to the evaluation of the expression stability of reference genes, the optimal number of internal reference genes for normalization is also proposed by geNorm software. geNorm calculated the pairwise variation $V$ value and proposed 0.15 as a cutoff value, below which the inclusion of an additional reference gene is not required. In this study, 8 out of 10 sample sets, except all samples and different tissues, showed pairwise variation $\mathrm{V} 2 / 3$ values below 0.15 , indicating that the combination of at least two reference genes was optimal for normalization among these sample sets. As for the analysis across all samples and among different tissues, the V2/3 was 0.1516 and 0.1674 , respectively. Considering that both were a little higher than 0.15 , and 0.15 value is not absolutely strict according to geNorm manual, we also inferred that at least two internal control genes should be used in these two sample sets.

To verify the reference genes stability selected by the three programs, the expression profiles of PsCHSI and PsCHII were assessed at different flower developmental stages in P. suffruticosa 'Yu Ban Bai' (white-flowered cultivar) (Fig. 5A and B). A similar expression pattern was obtained when using $P P 2 A$ and $A C T 2$ or the combination of them as reference genes. However, when using the least stable gene $T U B$, the expression pattern differed obviously from that by $P P 2 A$ and $A C T 2$. These results clearly demonstrated the suitability of the selected reference genes in gene expression analysis in tree peony under such experimental conditions as that in the current study and also indicated that using an unstable reference gene generated biases that could lead to misinterpretation of gene expression patterns.
To the best of our knowledge, this research is the first systematic analysis of suitable reference genes for normalization of gene expression analyses among different tissues and at different flower developmental stages of tree peony with different colors. Evaluations using geNorm, NormFinder, and BestKeeper revealed that different suitable reference genes should be used according to the different experimental sample sets. When all samples were considered together, $P P 2 A, U P L$, and $U B Q$ were identified as the most stable genes. Moreover, helicase, TUA, and EIF5A also exhibited high expression stability in different tissues, in samples with different colors, and at different flower developmental stages. According to the geNorm analysis, the combination of two most stable reference genes was optimal for normalization in all tested sample sets in this study. The expression pattern analyses of $P_{s} C H S 1$ and $P s C H I 1$ reinforce the necessity of validating reference genes for reliable normalization. This work contributes particularly for further study on the molecular mechanism of the flavonoid biosynthesis pathway and flower development of tree peony and serves as a guideline for the selection of reference genes in other Paeoniaceae family plants.

\section{Literature Cited}

Andersen, C.L., J.L. Jensen, and T.F. Ørntoft. 2004. Normalization of real-time quantitative reverse transcription-PCR data: A modelbased variance estimation approach to identify genes suited for normalization, applied to bladder and colon cancer data sets. Cancer Res. 64:5245-5250.

Artico, S., S.M. Nardeli, O. Brilhante, M.F. Grossi-de-Sa, and M. AlvesFerreira. 2010. Identification and evaluation of new reference genes in Gossypium hirsutum for accurate normalization of real-time quantitative RT-PCR data. BMC Plant Biol. 10:49-60.

Brunner, A.M., I.A. Yakovlev, and S.H. Strauss. 2004. Validating internal controls for quantitative plant gene expression studies. BMC Plant Biol. 4:14-20.

Bustin, S.A., V. Benes, J.A. Garson, J. Hellemans, J. Huggett, M. Kubista, R. Mueller, T. Nolan, M.W. Pfaffl, G.L. Shipley, J. Vandesompele, and C.T. Wittwer. 2009. The MIQE guidelines: Minimum information for publication of quantitative real-time PCR experiments. Clin. Chem. 55:611-622.

Chandna, R., R. Augustine, and N.C. Bisht. 2012. Evaluation of candidate reference genes for gene expression normalization in Brassica juncea using real time quantitative RT-PCR. PLoS One 7:e36918.

Chang, S., J. Puryear, and J. Cairney. 1993. A simple and efficient method for isolating RNA from pine trees. Plant Mol. Biol. Rpt. 11:113-116.

Chang, E., S. Shi, J. Liu, T. Cheng, L. Xue, X. Yang, W. Yang, Q. Lan, and Z. Jiang. 2012. Selection of reference genes for quantitative gene expression studies in Platycladus orientalis (Cupressaceae) using real-time PCR. PLoS One 7:e33278.

Coito, J.L., M. Rocheta, L. Carvalho, and S. Amâncio. 2012. Microarray-based uncovering reference genes for quantitative real time PCR in grapevine under abiotic stress. BMC Res. Notes 5:220231.

Czechowski, T., M. Stitt, T. Altmann, M.K. Udvardi, and W.R. Scheible. 2005. Genome-wide identification and testing of superior reference genes for transcript normalization in Arabidopsis. Plant Physiol. 139:5-17.

Demidenko, N.V., M.D. Logacheva, and A.A. Penin. 2011. Selection and validation of reference genes for quantitative real-time PCR in buckwheat (Fagopyrum esculentum) based on transcriptome sequence data. PLoS One 6:e19434.

Expósito-Rodríguez, M., A.A. Borges, A. Borges-Pérez, and J.A. Pérez. 2008. Selection of internal control genes for quantitative 
real-time RT-PCR studies during tomato development process. BMC Plant Biol. 8:131-142.

Freeman, W.M., S.J. Walker, and K.E. Vrana. 1999. Quantitative RT-PCR: Pitfalls and potential. Biotechniques 26:112-125.

Fu, J.X., Y. Wang, H. Huang, C. Zhang, and S. Dai. 2013. Reference gene selection for RT-qPCR analysis of Chrysanthemum lavandulifolium during its flowering stages. Mol. Breed. 31:205-215.

Ginzinger, D.G. 2002. Gene quantification using real-time quantitative PCR: An emerging technology hits the mainstream. Expt. Hematol. 30:503-512.

Guenin, S., M. Mauriat, J. Pellou, O. Van Wuytswinkel, C. Bellini, and L. Gutierrez. 2009. Normalization of qRT-PCR data: The necessity of adopting a systematic, experimental conditions-specific, validation of references. J. Expt. Bot. 60:487-493.

Heid, C.A., J. Stevens, K.J. Livak, and P.M. Williams. 1996. Real time quantitative PCR. Genome Res. 6:986-994.

Hong, Y. and S.L. Dai. 2015. Selection of reference genes for real-time quantitative polymerase chain reaction analysis of light-dependent anthocyanin biosynthesis in chrysanthemum. J. Amer. Soc. Hort. Sci. 140:68-77.

Hong, D.Y. and K.Y. Pan. 2005a. Notes on taxonomy of Paeonia sect. Moutan DC. (Paeoniaceae). Acta Phytotaxonomica Sinica 43:169-177.

Hong, D.Y. and K.Y. Pan. 2005b. Additional taxonomic notes on Paeonia sect. Moutan (Paeoniaceae). Acta Phytotaxonomica Sinica 43:284-287.

Hong, D.Y. and K.Y. Pan. 2007. Paeonia cathayana D.Y. Hong, and K. Y. Pan, a new tree peony, with revision of P.suffruticosa ssp. yinpingmudan. Acta Phytotaxonomica Sinica 45:285-288.

Hong, D.Y., K.Y. Pan, and H. Yu. 1998. Taxonomy of the Paeonia delavayi complex (Paeoniaceae). Ann. Mo. Bot. Gard. 85:554-564.

Huang, J., M. Gu, Z. Lai, B. Fan, K. Shi, Y.H. Zhou, J.Q. Yu, and Z. Chen. 2010. Functional analysis of the Arabidopsis $P A L$ gene family in plant growth, development, and response to environmental stress. Plant Physiol. 153:1526-1538.

Jain, M., A. Nijhawan, A.K. Tyagi, and J.P. Khurana. 2006. Validation of housekeeping genes as internal control for studying gene expression in rice by quantitative realtime PCR. Biochem. Biophys. Res. Commun. 345:646-651.

Jian, B., B. Liu, Y. Bi, W. Hou, C. Wu, and T. Han. 2008. Validation of internal control for gene expression study in soybean by quantitative real-time PCR. BMC Mol. Biol. 9:59-72.

Jin, X., J. Fu, S. Dai, Y. Sun, and Y. Hong. 2013. Reference gene selection for qPCR analysis in cineraria developing flowers. Sci. Hort. 153:64-70.

Klie, M. and T. Debener. 2011. Identification of superior reference genes for data normalisation of expression studies via quantitative PCR in hybrid roses (Rosa hybrida). BMC Res. Notes 4:518-526.

Kong, Q.S., J.X. Yuan, L.Y. Gao, S. Zhao, W. Jiang, Y. Huang, and Z.L. Bie. 2014. Identification of suitable reference genes for gene expression normalization in qRT-PCR analysis in watermelon. PLoS One 9: e90612.

Koo, S.C., O. Bracko, M.S. Park, R. Schwab, H.J. Chun, K.M. Park, J.S. Seo, V. Grbic, S. Balasubramanian, M. Schmid, F. Godard, D.J. Yun, S.Y. Lee, M.J. Cho, D. Weigel, and M.C. Kim. 2010. Control of lateral organ development and flowering time by the Arabidopsis thaliana MADS box Gene AGAMOUS-LIKE6. Plant J. 62:807-816.

Li, J.J. 1999. Chinese tree peony and herbaceous peony. China Forestry Publication House, Beijing, China.

Li, K., Y. Wang, B.Q. Zheng, X.T. Zhu, H.Z. Wu, and Q.Q. Shi. 2011. Pollen morphology of 40 Paeonia delavayi (Paeoniaceae) populations. J. Beijing For. Univ. 33:94-103.

Libault, M., S. Thibivilliers, D.D. Bilgin, O. Radwan, M. Benitez, S.J. Clough, and G. Stacey. 2008. Identification of four soybean reference genes for gene expression normalization. Plant Genome $1: 44-54$.

Lin, L., X. Han, Y. Chen, Q. Wu, and Y. Wang. 2013. Identification of appropriate reference genes for normalizing transcript expression by quantitative real-time PCR in Litsea cubeba. Mol. Genet. Genomics 288:727-737.

Lovdal, T. and C. Lillo. 2009. Reference gene selection for quantitative real-time PCR normalization in tomato subjected to nitrogen, cold, and light stress. Anal. Biochem. 387:238-242.

Mafra, V., K.S. Kubo, M. Alves-Ferreira, M. Ribeiro-Alves, R.M. Stuart, and L.P. Boava. 2012. Reference genes for accurate transcript normalization in citrus genotypes under different experimental conditions. PLoS One 7:e31263.

Mallona, I., S. Lischewski, J. Weiss, B. Hause, and M. Egea-Cortines. 2010. Validation of reference genes for quantitative real-time PCR during leaf and flower development in Petunia hybrida. BMC Plant Biol. 10:4-11.

Maroufi, A., E.V. Bockstaele, and M.D. Loose. 2010. Validation of reference genes for gene expression analysis in chicory (Cichorium intybus) using quantitative real-time PCR. BMC Mol. Biol. 11:15-27.

Migocka, M. and A. Papierniak. 2011. Identification of suitable reference genes for studying gene expression in cucumber plants subjected to abiotic stress and growth regulators. Mol. Breed. 28:343-357.

Nolan, T., R.E. Hands, and S.A. Bustin. 2006. Quantification of mRNA using real-time RT-PCR. Nat. Protoc. 1:1559-1582.

Paolacci, A.R., O.A. Tanzarella, E. Porceddu, and M. Ciaffi. 2009. Identification and validation of reference genes for quantitative RTPCR normalization in wheat. BMC Mol. Biol. 10:11-27.

Pfaffl, M.W., A. Tichopad, C. Prgomet, and T.P. Neuvians. 2004. Determination of stable housekeeping genes, differentially regulated target genes and sample integrity: BestKeeper-Excel-based tool using pair-wise correlations. Biotechnol. Lett. 26:509-515.

Reddy, D.S., P. Bhatnagar-Mathur, K.S. Cindhuri, and K.K. Sharma. 2013. Evaluation and validation of reference genes for normalization of quantitative real-time PCR based gene expression studies in peanut. PLoS One 8:e78555.

Reid, K.E., N. Olsson, J. Schlosser, F. Peng, and S.T. Lund. 2006. An optimized grapevine RNA isolation procedure and statistical determination of reference genes for real-time RT-PCR during berry development. BMC Plant Biol. 6:27-37.

Ren, X., Z. Chen, Y. Liu, H. Zhang, M. Zhang, Q. Liu, X. Hong, J.K. Zhu, and Z. Gong. 2010. ABO3, a WRKY transcription factor, mediates plant responses to abscisic acid and drought tolerance in Arabidopsis. Plant J. 63:417-429.

Shi, Q.Q., L. Zhou, Y. Wang, K. Li, B.Q. Zheng, and K. Miao. 2015. Transcriptomic analysis of Paeonia delavayi wild population flowers to identify differentially expressed genes involved in purple-red and yellow petal pigmentation. PLoS One 10:e0135038.

Silver, N., S. Best, J. Jiang, and S.L. Thein. 2006. Selection of housekeeping genes for gene expression studies in human reticulocytes using real-time PCR. BMC Mol. Biol. 7:33-41.

Udvardi, M.K., T. Czechowski, and W.R. Scheible. 2008. Eleven golden rules of quantitative RT-PCR. Plant Cell 20:1736-1737.

Vandesompele, J., K. De Preter, F. Pattyn, B. Poppe, N. Van Roy, A. De Paepe, and F. Speleman. 2002Accurate normalization of real-time quantitative RT-PCR data by geometric averaging of multiple internal control genes. Genome Biol. 3research0034.1-research0034.11.

VanGuilder, H.D., K.E. Vrana, and W.M. Freeman. 2008. Twenty-five years of quantitative PCR for gene expression analysis. Biotechniques 44:619-626.

Wang, Z., Y. Chen, H. Fang, H. Shi, K. Chen, Z. Zhang, and X. Tan. 2014a. Selection of reference genes for quantitative reversetranscription polymerase chain reaction normalization in Brassica napus under various stress conditions. Mol. Genet. Genomics 289:1023-1035.

Wang, Y.J., L. Dong, C. Zhang, and X.Q. Wang. 2012. Reference gene selection for realtime quantitative PCR normalization in tree peony (Paeonia suffruticosa Andr.). J. Agr. Biotechnol. 20:521-528.

Wang, T.R.J., H.T.P. Hao, T.R. Cheng, and Q.X. Zhang. 2014 b. Selection of suitable reference genes for quantitative real-time polymerase chain reaction in Prunus mume during flowering stages 
and under different abiotic stress conditions. J. Amer. Soc. Hort. Sci. 139:113-122.

Xu, M., B. Zhang, X. Su, S. Zhang, and M. Huang. 2011. Reference gene selection for quantitative real-time polymerase chain reaction in Populus. Anal. Biochem. 408:337-339.

Yi, S., Y. Qian, L. Han, Z. Sun, C. Fan, J. Liu, and G. Ju. 2012. Selection of reliable reference genes for gene expression studies in Rhododendron micranthum Turcz. Sci. Hort. 138:128-133.
Zhou, L., Y. Wang, and Z. Peng. 2011. Molecular characterization and expression analysis of chalcone synthase gene during flower development in tree peony (Paeonia suffruticosa). Afr. J. Biotechnol. 10:1275-1284.

Zhou, L., Y. Wang, L. Ren, Q. Shi, B. Zheng, K. Miao, and X. Guo. 2014. Overexpression of Ps-CHI1, a homologue of the chalcone isomerase gene from tree peony (Paeonia suffruticosa), reduces the intensity of flower pigmentation in transgenic tobacco. Plant Cell Tissue Organ Cult. 116:285-295. 


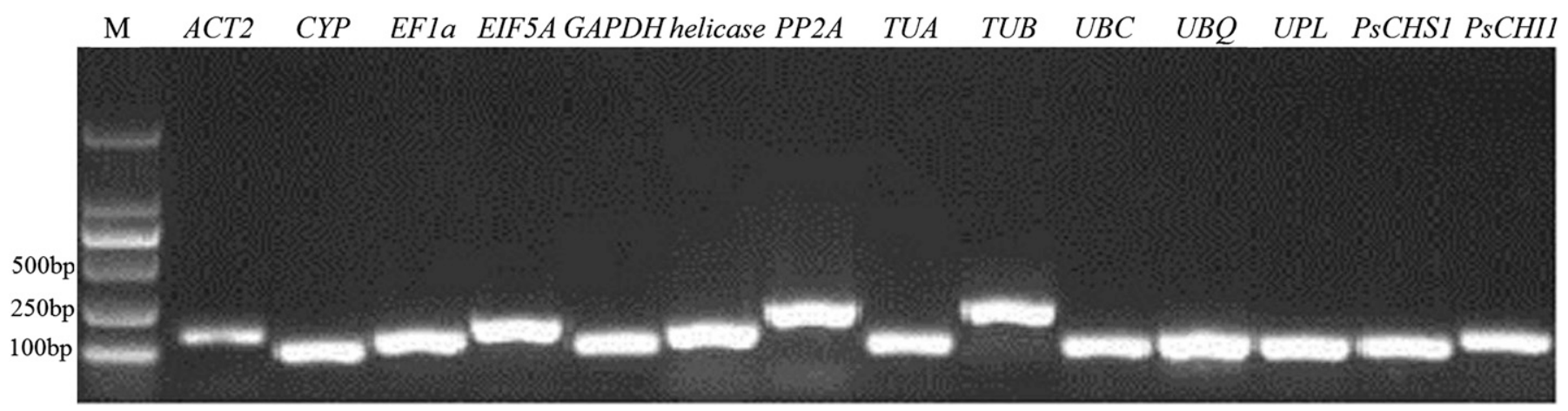

Supplemental Fig. 1. Quantitative real-time polymerase chain reaction amplification specificity of the 12 reference genes, $P s C H S 1$, and $P S C H I 1$. Only a single amplification product for each primer pair with the expected amplicon size was verified by $1.8 \%$ agarose gel electrophoresis. $\mathrm{M}=$ marker DL2000, ACT2 $=$ actin2 gene, $C Y P=$ cyclophilin gene, $E F 1 \alpha=$ elongation factor 1 -alpha gene, $E I F 5 A=$ eukaryotic translation initiation factor $5 \mathrm{~A}$ gene, $G A P D H=$ glyceraldehyde-3phosphate dehydrogenase gene, $P P 2 A=$ protein phosphatase $2 \mathrm{~A}$ gene, $T U A=$ alpha-tubulin gene, $T U B=$ beta-tubulin gene, $U B C=$ ubiquitin-conjugating enzyme E2 gene, $U B Q=$ ubiquitin gene, $U P L=$ ubiquitin protein ligase gene, $P S C H S 1=$ a chalcone synthase homolog gene of arabidopsis, $P S C H I 1=$ a chalcone isomerase homolog gene of arabidopsis. 
ACT2

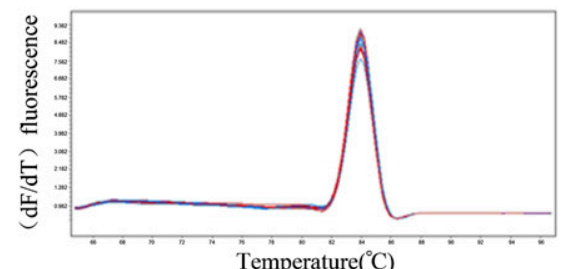

EF1a

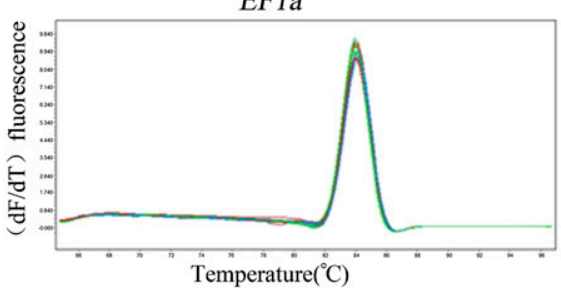

GAPDH

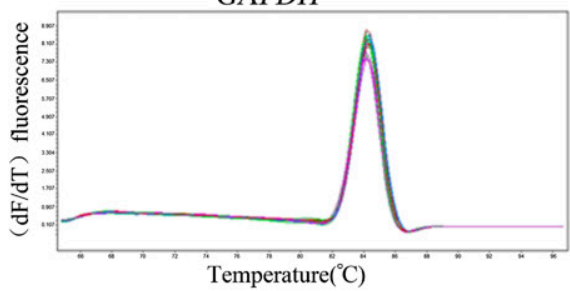

PP2A

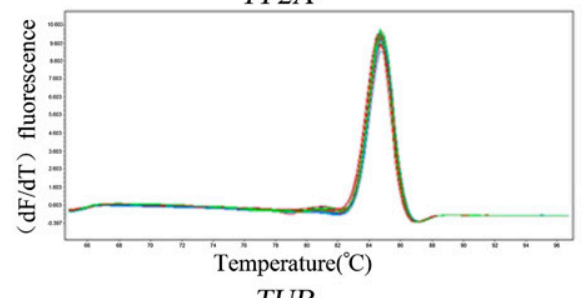

TUB

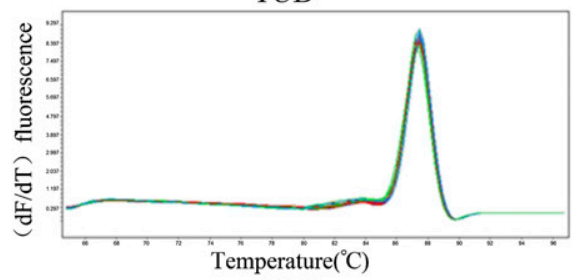

$U B Q$

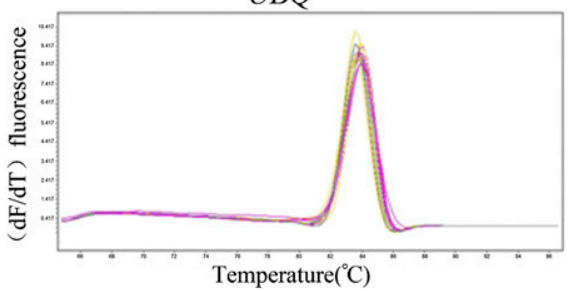

$\mathrm{PsCHI}_{1}$

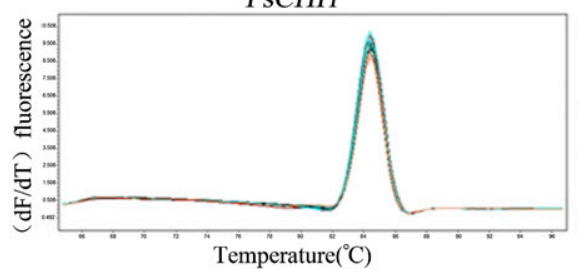

CYP

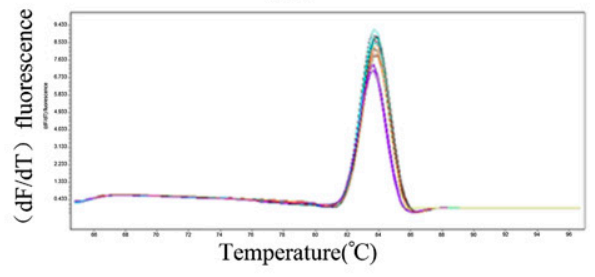

EIF5A

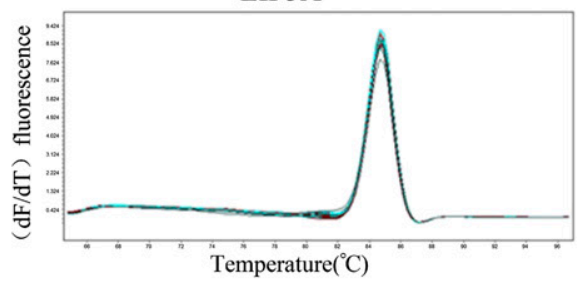

helicase

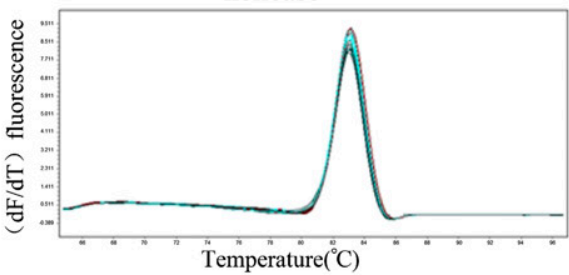

TUA

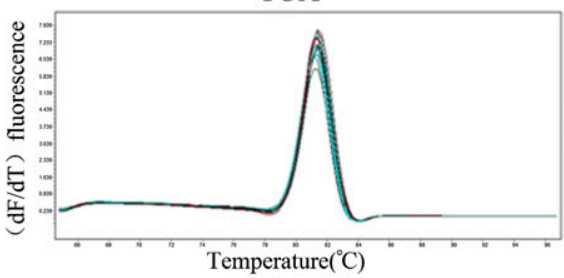

$U B C$

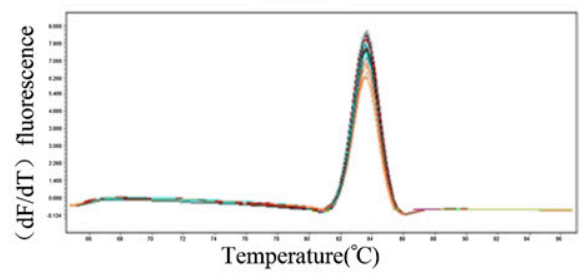

UPL

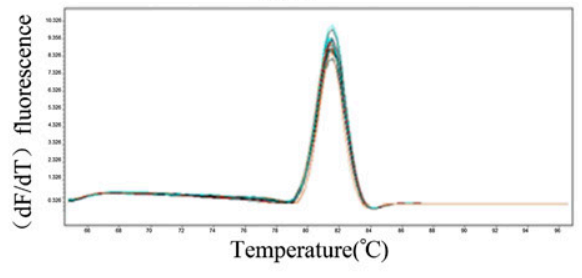

PsCHS1

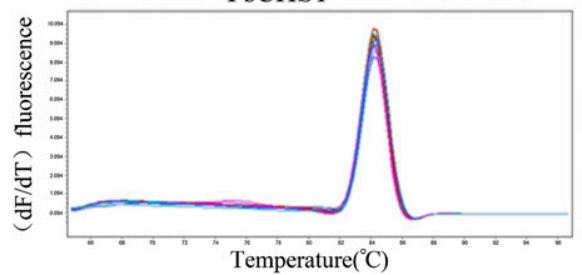

Supplemental Fig. 2. Melting curves of the 12 reference genes, $P S C H S 1$, and $P S C H I 1$. $A C T=$ actin2 gene, $C Y P=$ cyclophilin gene, $E F 1 \alpha=$ elongation factor 1 -alpha gene, $E I F 5 A=$ eukaryotic translation initiation factor $5 \mathrm{~A}$ gene, $G A P D H=$ glyceraldehyde-3-phosphate dehydrogenase gene, $P P 2 A=$ protein phosphatase $2 \mathrm{~A}$ gene, $T U A=$ alpha-tubulin gene, $T U B=$ beta-tubulin gene, $U B C=$ ubiquitin-conjugating enzyme $\mathrm{E} 2$ gene, $U B Q=$ ubiquitin gene, $U P L=$ ubiquitin protein ligase gene, $P S C H S 1=$ a chalcone synthase homolog gene of arabidopsis, $P S C H I 1=$ a chalcone isomerase homolog gene of arabidopsis, temperature $\left({ }^{\circ} \mathrm{C}\right)=$ the amplification temperature, $\mathrm{dF} / \mathrm{dT}$ fluorescence $=$ derivative of fluorescence with respect to temperature. 

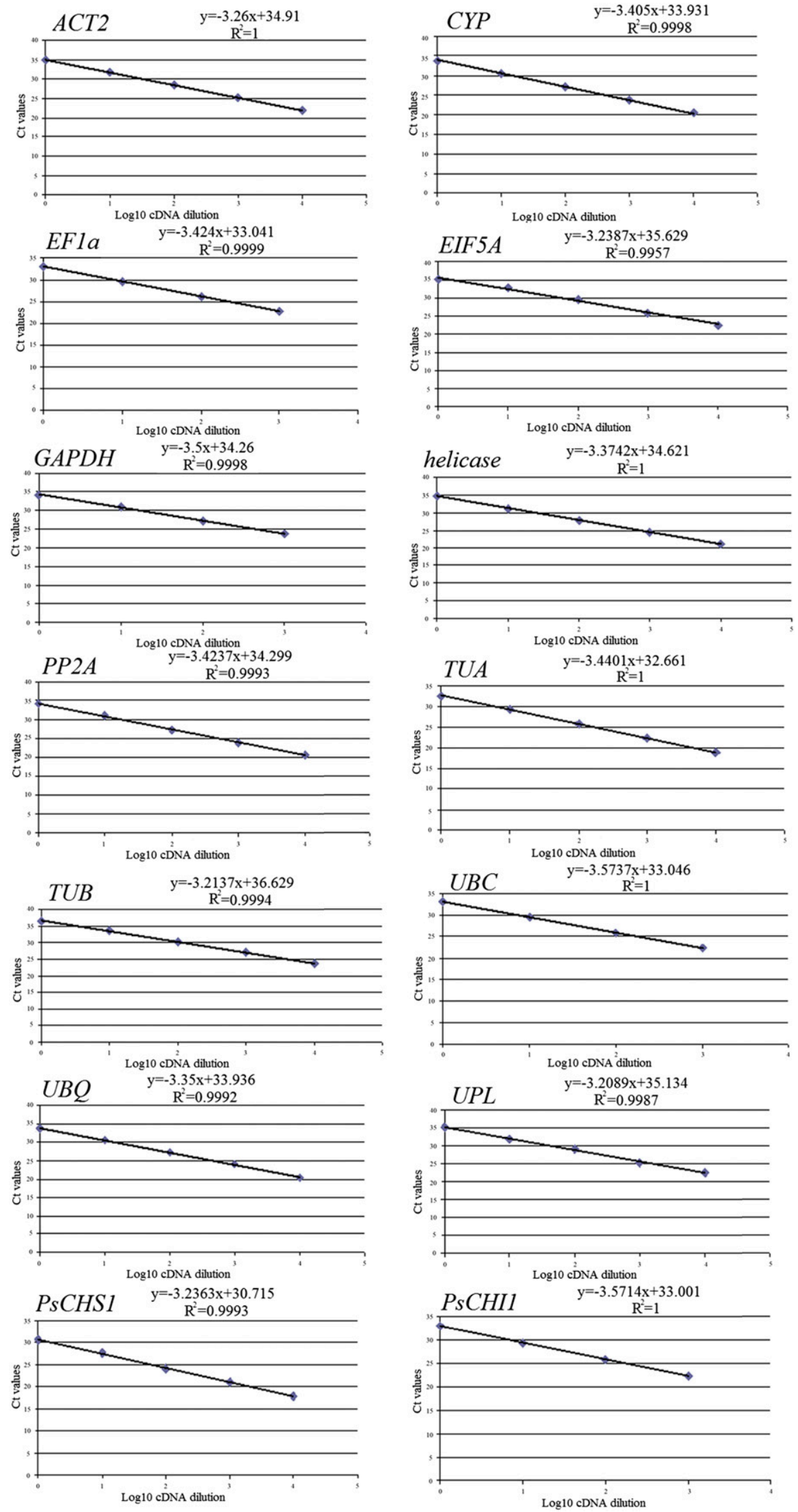

Supplemental Fig. 3. Amplification efficiencies of the 12 reference genes, $P S C H S 1$, and $P s C H I 1 . A C T=$ actin 2 gene, $C Y P=$ cyclophilin gene, $E F 1 \alpha=$ elongation factor 1-alpha gene, $E I F 5 A=$ eukaryotic translation initiation factor $5 \mathrm{~A}$ gene, $G A P D H=$ glyceraldehyde-3-phosphate dehydrogenase gene, $P P 2 A=$ protein phosphatase $2 \mathrm{~A}$ gene, $T U A=$ alpha-tubulin gene, $T U B=$ beta-tubulin gene, $U B C=$ ubiquitin-conjugating enzyme $\mathrm{E} 2$ gene, $U B Q=$ ubiquitin gene, $U P L=$ ubiquitin protein ligase gene, $P_{S} C H S 1=$ a chalcone synthase homolog gene of arabidopsis, $P S C H I 1=$ a chalcone isomerase homolog gene of arabidopsis. 


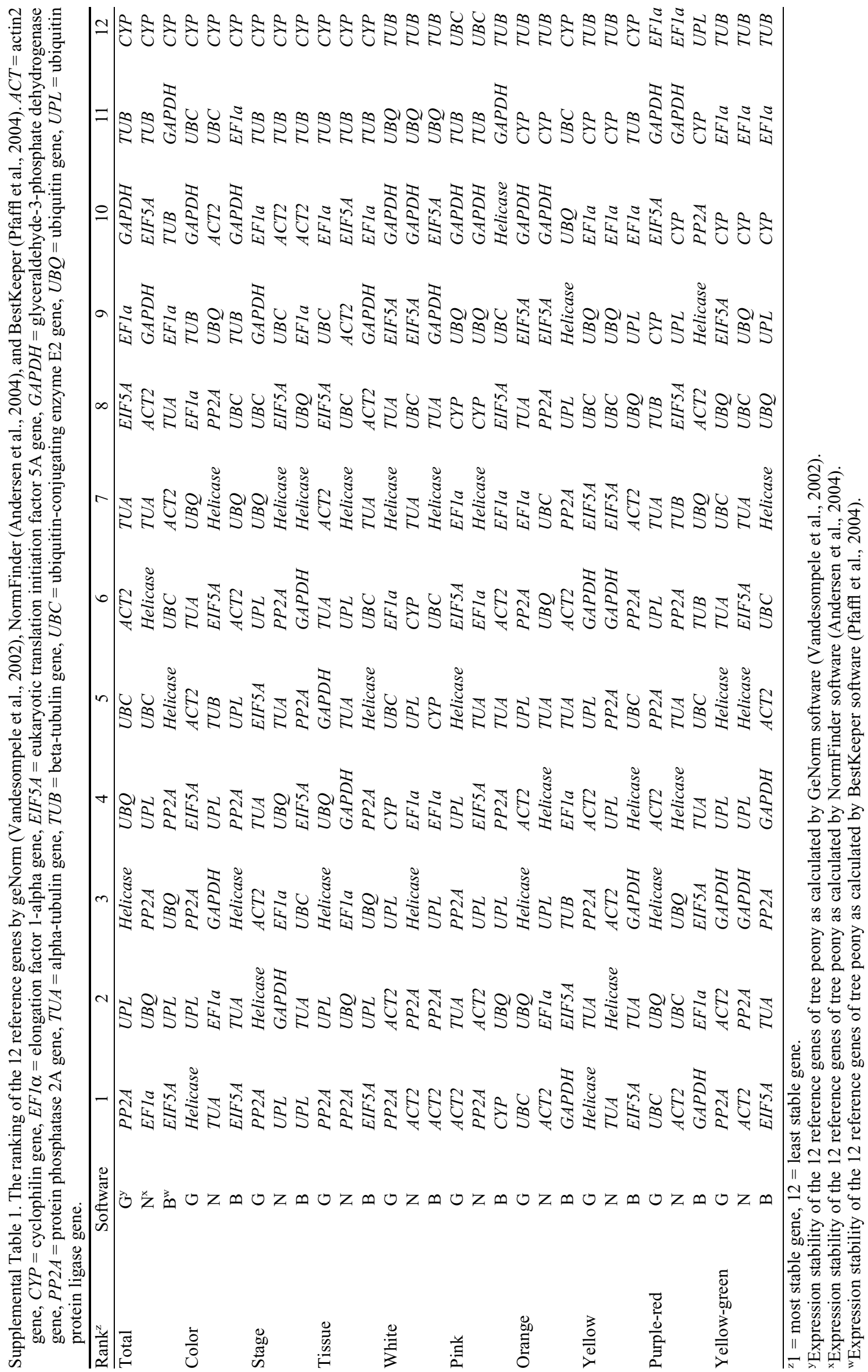


Supplemental Table 2. List of sequences of candidate reference genes, $P S C H S 1$, and $P S C H I 1 . A C T=$ actin2 gene, $C Y P=$ cyclophilin gene, $E F 1 \alpha=$ elongation factor 1 -alpha gene, $E I F 5 A=$ eukaryotic translation initiation factor $5 \mathrm{~A}$ gene, $G A P D H=$ glyceraldehyde-3phosphate dehydrogenase gene, $P P 2 A=$ protein phosphatase $2 \mathrm{~A}$ gene, $T U A=$ alpha-tubulin gene, $T U B=$ beta-tubulin gene, $U B C=$ ubiquitin-conjugating enzyme $\mathrm{E} 2$ gene, $U B Q=$ ubiquitin gene, $U P L=$ ubiquitin protein ligase gene, $P S C H S 1=$ a chalcone synthase homolog gene of arabidopsis, $P S C H I 1=$ a chalcone isomerase homolog gene of arabidopsis.

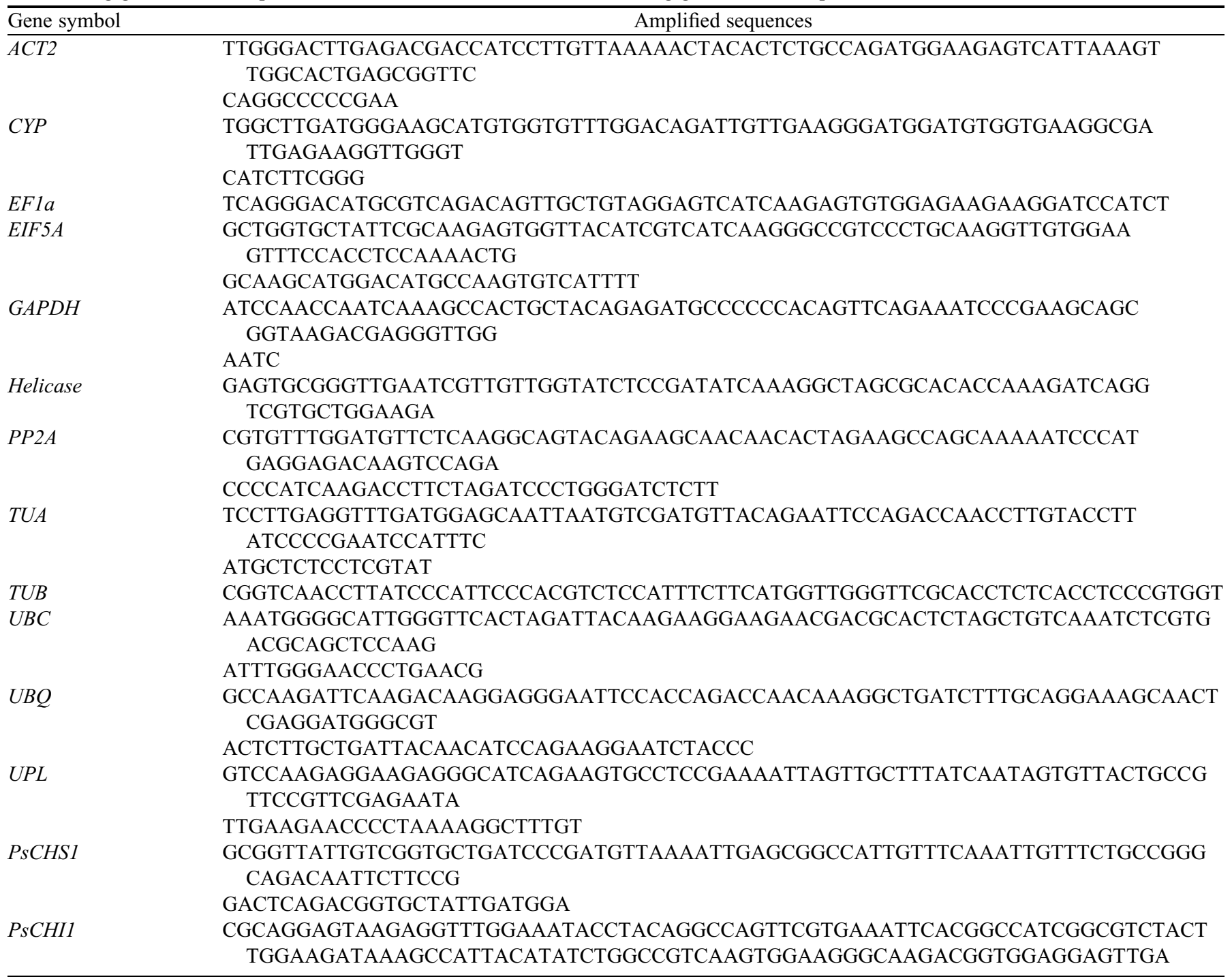

